\title{
The Effectiveness of Resiliency Training Program on the Components of Quality of Life in Mothers with Hearing-Impaired Children
}

\author{
${ }^{1}$ L. Aslani, ${ }^{2}$ M. Azkhosh, ${ }^{3}$ G.Movallali, ${ }^{4}$ S.J.Younesi, ${ }^{5}$ Z. Salehy \\ (University of Social Welfare and Rehabilitation Sciences, Tehran, Iran)
}

\begin{abstract}
The birth of a child with hearing impairment in a family will cause chaos and inconvenience among family members. This will affect the quality of life and welfare of parents. The present study aims to investigate the effectiveness of a resilience-raising programme on the components of the quality of life in mothers with hearing-impaired children. This study is quasi-experimental with a pre-test, a post-test and a control group. The sample population includes all the mothers with hearing-impaired children in district 13 of Tehran's municipality. These mothers were selected using the convenience sampling method from a hearing impairment centre in the district. The samples were randomly assigned in the experimental group $(n=15)$ and the control group $(n=15)$. The resilience questionnaire by Conner and Davidson the short form of the parental stress index by Abidin and the parent-child relationship questionnaire by Forman were used in the pretest and posttest. The experimental group was treated with a "resilience-raising programme" in 9 sessions of 90 minutes each. The results were analysed using ANCOVA in SPSS. The results suggested that the degree of resilience and improvement of mother-child relationships were significantly higher in mothers treated with this programme compared with those who were not, and the group's parental stress was lowered. The resilience-raising programme can be effective in improving the quality of life in mothers with hearing-impaired children.
\end{abstract}

Keywords: Life quality, resilience, mothers, hearing-impaired

\section{Introduction}

When people understand that their child has a hearing impairment, they react differently. Some parents feel disappointed; others become suspicious and despaired [1]. Mothers with hearing-impaired children undergo more stress than those mothers with normal children and are more depressed [2]. There are similarities between the stressful psychological circumstances in those with psychosomatic complications and the daily challenges facing mothers with impaired children, i.e. these parents often find themselves in difficult situations and diminishing their mental and physical strength [3].

According to international statistics regarding the infants, 1 to 3 per 1000 infants would have hearingimpairment [4]. In comparison with mothers of normal kids, mothers with hearing-impaired children are more susceptible to mental and physical complications and are less resilient [5].

In sum, having hearing-impaired children affects the factors of quality of life of the parents. Quality of life is a concept with various definitions. One such definition is presented by the WHO (1993) in which quality of life is defined as a multidimensional structure including assessment of at least three dimensions of emotional well-being, physical condition, and social performance.

Resilience capacity is a positive and desirable feature and is considered dynamic and flexible and can be enhanced using a host of approaches such as strengthening protective factors or establishing new protective factors [6]. Kalil [7] expressed that people's resilience can be increased by reducing of risk elements, by having less exposures to these elements, by increasing adaptability and coping with stress, by strengthening protective factors in families, and by improving self-esteem and self-sufficiency.

Many studies have been conducted on resilience. For instance, Steensma, Heijer and Stallen [8] found that by teaching people to be resilient, they could increase their use of positive coping strategies such as using active approaches, seeking social support, using self-encouraging and positive thinking. On the other hand, they could reduce their use of negative coping strategies such as using depressive reactions, being passive, using refraining approaches, and supressing their depression.

Despite a host of suggestions, few experimental studies have dealt with resilience programmes against stress and its effects on the quality of life in mothers with special-needs children. Because of the negative effect of hearing-impaired children on their mothers, it is necessary that mothers with hearing-impaired children be given to follow intervention programmes to reduce their stress and improve their quality of life.

If the resilience teaching programme can improve the quality of life in these mothers, the results can be of use to parents, psychologists, and counsellors who deal with these families. In this study, a programme for resilience against stress in mothers with hearing-impaired children was conducted in district 13 of Tehran's 
municipality during 2013 and the effects of this program on social, emotional and psychological factors of life quality were assessed.

\section{Materials and Methods}

The present study is quasi-experimental with pretest, posttest and a control group. The sample population includes the mothers with hearing-impaired children in district 13 of Tehran's municipality who's selected by convenience sampling. Due to possible rejection and drops in the number of participants, firstly, 36 participants were selected for the study. Then, three of them were rejected because of more than three session's absence; two participants were rejected because of not filling the questionnaire and one participant also dropped out of the study. Finally, 15 participants took part in two groups. One group was randomly selected as the experimental group and treated with 9 sessions of resilience class, each 90 minutes, once a week. In another group as a control group no intervention was considered. At the end, posttest was administered on both groups and ANCOVA in SPSS was used for statistical data analysis. The instruments in this study were a Parental Stress Index (PSI) short form (SF) and a 40-items questionnaire for parent-child relationship life satisfaction scale.

\subsection{Parental Stress Index short form (PSI/SF)}

The Parental Stress Index short form (PSI/SF) is a 36-questions scale compiled by Abidin [9].It was administered by a series of replicated factors analyses. This factor analysis led to a three-factor solution as the best describer of data. Reviewing any of the test's questions indicates that appropriate titles for these factors are: 1. Parental Distress factor (PD), 2. Parent-Child Dysfunctional Interaction factor (PCDI), 3. Difficult Child factor (DC).

Reliability and normalizing calculations were done for Parental Stress Index short form. The reliability estimation was done via two approaches of test-retest and internal consistency for the sub-scales. The alpha value for combined scale is reported at .91 [9]. Reliability by test-retest was done on 530 mothers with a 6monthstime's interval and a total stress factor reliability coefficient of .84 . The alpha coefficient for total stress scale was calculated using the normal sample of 800 at .91 . Using the same sample, the alpha coefficient for the sub-scales of Parental Distress, Parent-Child Dysfunctional Interaction and Difficult Child were .87, .80 and .85. In a study by Roggman, Moe, Hart and Forthun (1994), 103 parents participated and reliability for the aforementioned sub-scales was calculated at $.79, .80$ and .78 , with the reliability of the total stress at .90 (Cited in [10]).

\subsection{Parent-Child Relationship Questionnaire (PCRQ)}

The 40-items Parent-Child Relationship Questionnaire, prepared by Forman with 19 sub-scales. It measures five factors of Warmth (W), Personal Relationships (PR), Disciplinary Warmth (DW), Power Assertion (PA) and Possessiveness (P) which has been achieved through factor analysis from the 19 sub-scales. The reliability correlation coefficient of this scale using Cronbach Alpha is calculated at.82. In order to measure the concurrent validity of the PCRQ by Forman, some of the items were correlated with those of PCRQ questionnaire by Robinson. The observed correlation coefficient between the W factors in Forman's PCRQ was .96 with the child rearing approaches in Robinson's PCRQ. The same figure between DW factor in Forman's PCRQ and regulatory factor (deduction/induction) factor in Robinson's PCRQ stood at .93 and this rate was .93 between Forman's P factor and Robinson's physical obligations and verbal aggression [10].

\subsection{The resilience scale by Conner and Davidson}

In order to measure the resilience scale, Conner and Davidson resilience scale was used. This questionnaire was developed by Connor and Davidson [11]. Mohammadi [12] calculated the reliability of this questionnaire using Crobnach's alpha at .89. The validity was calculated using factor analysis and showed from .14 to .64 (except 3 questions). Thus, 21 factor analyses were used in the final evaluation.

\section{Findings}

The mothers who took part in this study were 30 between 21 and 41 years old and average of 29.67. Nine of these mothers $(30 \%)$ had junior high diploma, 17 (56.7\%) had senior high diploma and 4 (13.3\%) possessed a bachelor's degree. 
Table 1.The Mean and Standard Deviation of Resilience Standard, Parental Stress and Parent-Child Relationship in Both Control and Experimental Group

\begin{tabular}{|c|c|c|c|c|}
\hline & \multicolumn{2}{|c|}{ Experimental group } & \multicolumn{2}{|c|}{ Control group } \\
\hline Variables & $\mathrm{X}$ & $\mathrm{S}$ & $\mathrm{X}$ & $\mathrm{S}$ \\
\hline Resilience pretest & 35.40 & 3.536 & 33.87 & 4.299 \\
\hline Resilience posttest & 63.53 & 3.570 & 36.60 & 4.401 \\
\hline Stress pretest & 94.33 & 4.196 & 95.13 & 5.646 \\
\hline Stress posttest & 125.13 & 3.831 & 98 & 5.855 \\
\hline Relationship pretest & 114.80 & 6.306 & 115 & 6.890 \\
\hline Relationship posttest & 129.6 & 4.291 & 118.3 & 6.4 \\
\hline
\end{tabular}

In order to assess the effect of stress resilience program on mothers with hearing-impaired children and their quality of life, multi variable ANCOVA was used.

Table 2.CovarianceAnalysis for the Effect of Stress Resilience Program on Quality of Life in Mothers with Hearing-Impaired Children

\begin{tabular}{|l|l|l|l|l|l|}
\hline Variables & Wilks Lambda & F & Sig & $2 \eta$ & Power \\
\hline Test & & & & & .99 \\
\hline Effect of group & .11 & 58.42 & .000 & .88 & .99 \\
\hline
\end{tabular}

The results of ANCOVA showed that the stress resilience program for mothers with hearing-impaired children significantly influences on the factors of quality of life $\left(p<0.01, \mathrm{~F}_{1,28}=58.42\right)$.

Table 3. Results of One-Way Covariance Analysis on the Factors of Quality of Life

\begin{tabular}{|l|l|l|l|l|l|l|}
\hline $\begin{array}{l}\text { Dependent } \\
\text { variable }\end{array}$ & Sum of squares & df & Mean squares & F & Sig \\
\hline Stress & 5796.22 & 1 & 5796.22 & 72.56 & .000 & \\
\hline Relationship & 996.93 & 1 & 996.93 & 11.24 & .003 & .31 \\
\hline
\end{tabular}

Analysis of each dependent variables using corrected Ben Feroni's Alpha (.005) showed that mothers with hearing-impaired children treated with stress resilience program had significant statistical differences in parental stress $\left(\mathrm{F}_{1,28}=72.56, p=.000\right)$ and relationship $\left(\mathrm{F}_{1,28}=11.24, p=.000\right)$. This means that the stress resilience program influenced the factors of life quality in mothers with hearing-impaired children.

\section{Discussion and Conclusion}

The results of the study showed that stress resilience programme influenced the factors of life quality in mothers with hearing-impaired children $(p=.000)$. Other studies by Steensma, Heijer, and Stallen [8]; [13]; $[14] ;[15] ;[16]$ found that resilience improvement programmes will increase the effectiveness of countering strategies, ultimately boosting the resilience of these mothers.

Masten [17] believed that resilience will enable people to handle unpleasant incidents to achieve positive outcomes and contribute to the person's health. Resilience increases people's capability and potential for change, regardless of threatening dangers. Friborg, Hjmedal, Rosenvinge, Martinusen, and Aslaksen [18] said that resilience could reduce anxiety, psychological pressure, and depression. They believed that resilience enables people to overcome adverse effects.

In explication of the findings of this study, it can be said that the resilience programme increases optimism in individuals. The programme makes optimists feel secure and stable when facing challenging circumstances, and they are believed to behave successfully against hardships [19]. One other reason that may cause the positive influence of this programme is that it alters knowledge, mentality, and spiritual attitudes of mothers. As Poston and Turnbull [20] pointed out, assigning meaning to the caring of these children and the related spiritual issues would help them keep feeling calm and would enable them to face difficult situations.

According to this study, the resilience programme is effective in improving the mother-child relationship. This section of findings is in agreement with the ideas of Kordich Hall, and Pearson [21]; [22]; [23] who believed that resilience will improve relationships with others and will contribute to having merrier relationships. One reason that may cause the resilience programme to be effective on the parent-child relationship is that parental stress will cause negative outcomes in parent-child interactions. Abidin [9] asserted that parental stress is a significant factor in determining the quality of parent-child interactions. The present literature suggests that stress influences child-rearing process. The resilience programme creates changes in attitudes, manners and skills of mothers, enabling them to relate better to their children and this helps mothers not to easily surrender to the problems arising from the problems of caring and bringing up their children and preventing such problems from affecting their lives. 
According to this study resilience programme is effective in reducing resilience. This part of findings is consistent with that of Judkins and Riend [24]; [25]; [17]; [14]; [26]; [27]. Wyman [28] studied 82 students regarding the balancing role of resilience on mental pressure. The results of the study showed that resilience balances mental pressure. This balance happens in the process of a conformity assessment of psychological pressure. Creating resilience via establishing psychological acceptance leads to decreasing the psychological pressure due to work and work places [29].

In explaining the findings of this study, group teaching has been found to have a positive effect in decreasing psychological pressure, because people in groups will individually feel that others share the same problems as them. Therefore, when they use each other's experience to cope with stress, it is helpful in reducing psychological pressure and in boosting self-confidence. Resilience can guarantee and improve psychological health of people [30].

In sum, the findings of this study showed that resilience-raising programme influences factors of quality of life and improves them. The resilience programmes will lead to the establishment of coping approaches and better defence mechanisms in individuals and in this way improve the quality of life. Finally, the results of this study indicated that one of the most important resilience-raising approaches is to change the attitudes of people with special-needs children towards life, because when a person's mentality changes, his or her manners will change as well. The results of this study approve this. So this study suggests that one of the best ways of changing attitudes is teaching resilience; and the sooner and more comprehensive this teaching is provided, the more influential it will be. In many countries, resilience programmes are administered at the early ages in the kindergarten and elementary schools for lasting effects. Furthermore, in some countries, parents are given resilience trainings to be used since the birth of their children, as a foundation for children rearing.

\section{Acknowledgment}

The authors wish to acknowledge the troubles of the kind mothers who generously and compassionately cooperated in the conduct of this study.

\section{REFERENCES}

[1]. G. Movallali, My child is hearing-impaired, (Welfare and Rehabilitation University Press, Iran, 2011).

[2]. Zamani, and S. Hosseini, The psychological effect of a deaf child on family, Journal of Exceptional Education, 83(1), $2008,8-9$.

[3]. R.F. Schilling, and S.P. Schinke, Personal coping and social support for parents of handicapped children, Children and Youth Services Review, 6(1), 1984, 195-206.

[4]. M. Marschark, Raising and education a deaf child (Oxford University Press, New York, 2007).

[5]. M. Ghodrati and Mirkouhi, Parental stress in parents of deaf students: stressful factors, strategies to cope with stress and hardiness, masterdiss, Tehran University, Iran, 2001.

[6]. K.A. Drummond, and I. Mcdonald, Family adaptation: The goal of promoting resiliency in head start families. NHSA dialog, 1(3), 1997, 132-151.

[7]. Kalil, Family resilience and good child outcomes: A review of the literature. Wellington: Center for social research and evaluation, Ministry of social development, 2003.

[8]. H. Steensma, M.D. Heijer, and V. Stallen, Effects of resilience training on the reduction of stress and depression among Dutch workers. Quarterly of community health education, 2007.

[9]. R.R. Abidin, Parenting Stress Index ( $3^{\text {rd }}$ Ed). Psychological assessment resource (INC: Lutz, Florida, 1995.

[10]. M. Kaveh, Compiling a stress resilience raising program and the effect of teaching it on factors of life quality in parents of children with mild mental disability, doctoral diss, Allameh Tabatabai University, Iran, 2009.

[11]. K.M.Connor and J.R.T.R. Davidson, Development of a new resilience scale (www.ncbi.nlm.nih.gov/pubmed/12964174).

[12]. M. Mohammadi, Assessing the influential factors on the resilience of those susceptible to drug abuse, doctoral diss, Welfare and Rehabilitation University, Iran, 2005.

[13]. M. Steinhard, and C. Dolbier, Evaluation of a resilience intervention to enhance coping strategies and protective factors and decrease symptomatology, Journal of American College Health, 56(4), 2008,445-45.

[14]. H. McGrath, The Bounce Bac! Resiliency program: A pilot study, paper presented at the American educational research association annual conference, New Orleans, April 24-28, 2000.

[15]. O. Jahed, Determining effectiveness of resilience teaching on mental pressure of female high school students in dormitories, master diss, Welfare and Rehabilitation University, Iran, 2012.

[16]. Z. Oloumi yazdi, and H. Salimi Bejestani, Effectiveness of resilience teaching on the quality of life of mothers with 10 to 13 - yearold children suffering from cancer in Imam Khomeini hospital, master diss, Allameh Tabatabai University, Iran, 2009.

[17]. A.S. Masten, Resilience and development: Contributions from the study of children who overcome adversity. Journal of Development and Psychopathology, 2(4), 2001, 425-444.

[18]. O. Friborg, O. Hjmedal, O. H. Rosenvinge, M. Martinusen, and M. Aslaksen, Resilience as a moderator of pain and stress. Journal of Psychosomatic Research,61(1), 2006, 213-219.

[19]. C.R. Snyder, and J. Lopez, Handbook of positive psychology (Oxford University Press, New York, 2002).

[20]. D.J. Poston, and A. Turnbull, Role of spirituality and religion in family quality of life, Education and Training in Developmental Disabilities,39(2), 2004, 95-108.

[21]. D. Kordich Hall and J. Pearson, Resilience, giving children the skills to bounce back, reaching out project publishers, Antario, 2005 .

[22]. P.J. Waite, Determining the efficacy of resiliency training in the work site, Journal of Allied Health, 33(3), 2004, 178-183.

[23]. R. Mackay, Family resilience and good child outcomes: An overview of the research literature. Social Policy Journal of New Zealand, 20(1), 2003, 98-118. 
[24]. S, Judkins, and B. Riend, Decreasing stress among nurse managers: Building a healthy workplace. The Journal of Continuing Education in Nursing, 37(5), 2006, 202-207.

[25]. A. Abolghasemi, Relationship of resilience, stress and self-sufficiency with life satisfaction in students with varying educational progressions. Psychological Studies Journal, 7(3),2011.

[26]. R. Behlmann, and I.D. Dinter, Encouraging self- encouragement: An effect study of the encouraging-training shoemaker-concept. The Journal of Individual Psychology, 57(3), 2001, 273-288.

[27]. M. Rice, The effects of a structured hardiness training intervention program for stress on university women, unpublished doctoral diss, Brigham Young University, 1997.

[28]. P.A.Wyman, Development and family milieu correlates of resilience in urban children who have experienced major life stress. American Journal of Community Psychology, 19(1), 1991, 405-426.

[29]. S.J. Noone, and R.P. Hastings, Building psychological resilience in support staff caring for people with intellectual disabilities: Pilot evaluation of an acceptance-based intervention, Journal of Intellect Disability, 13(1), 2009, 43-53.

[30]. M. Pinquart, Moderating effects of dispositional resilience on associations between hassles and psychological distress, Journal of Applied Developmental Psychology, 30(1), 2009, 53-60. 